\title{
Helikopter Anababalık ve Özerklik Destekleyici Davranışlar Ölçeği'nin Türkçeye Uyarlanması: Geçerlik ve Güvenirlik Çalışması ${ }^{1}$
}

\begin{tabular}{lccc}
\hline MAKALE TÜRÜ & Başvuru Tarihi & Kabul Tarihi & Yayım Tarihi \\
Araştırma Makalesi & 25.02 .2021 & 02.03 .2022 & 03.03 .2022 \\
\hline
\end{tabular}

\author{
Figen Çok (iD ${ }^{2}$, Cansu Hazal Güçlü (iD ${ }^{3}$, Hatice Kübra Özdoğan (iD ${ }^{4}$ ve \\ Semih Topuz \\ Başkent Üniversitesi
}

\section{Öz}

Bu çalışmanın amacı Schiffrin, Liss, Miles-McLean, Geary, Erchull ve Tashner tarafindan geliştirilen Helikopter Anababalık ve Özerklik Destekleyici Davranışlar Ölçeği’nin (HAÖDD) Türkçeye kazandırılması, geçerlik ve güvenirliğinin incelenmesidir. Ölçeğin özgün formu helikopter anababalık ve özerklik destekleyici davranışlar olmak üzere iki alt boyut ve 15 maddeden oluşmaktadır. Yazarlarla bağlantı, onay alma ve çeviri süreçlerinin ardından ölçeğin uyarlama süreçlerine uygun son biçimi altılı likert form olarak 381 (\%78) kadın 107 (\%22) erkek olmak üzere toplam 488 üniversite öğrencisine uygulanmış ve sonuçlar değerlendirilmiştir. Ölçeğin geçerliği için kanıt elde etmek amacıyla yapılan doğrulayıcı faktör analizi sonucunda özgün ölçekte belirlenen iki boyutlu yapıyla iyi uyum gösterdiği belirlenmiştir $\left(\chi^{2}=223.02, \mathrm{df}=87, \chi^{2} / \mathrm{df}=2.56, \mathrm{p}<.001, \mathrm{RMSEA}=.060\right.$, SRMR $=.070$, CFI $=.97, \mathrm{NNFI}=.96, \mathrm{NFI}=.95, \mathrm{GFI}=.98)$. Ölçeğin güvenirliğine yönelik kanıtlar bulmak amacıyla Cronbach alfa iç tutarlılık katsayısı hesaplanmış ve helikopter anababalık boyutu için $\alpha=.80$ ve özerklik destekleyici davranışlar boyutu için $\alpha=.80$ bulunmuştur. Maddelerin, toplam puanı yordamasına ilişkin madde-toplam korelasyonları incelendiğinde korelasyonların .31-.64 arasında değiştiği görülmüştür. Tüm maddelerde, üst-alt \%27'lik grupların ortalamaları arasında anlamlı fark bulunmuştur. Sonuç olarak 15 maddeden oluşan Helikopter Anababalık ve Özerklik Destekleyici Davranışlar Ölçeği'nin Türkiye'deki üniversite öğrencilerinin bakış açısıyla anababaların helikopter anababalık ve özerklik destekleyici davranışlarını ölçmede geçerli ve güvenilir bir ölçme aracı olduğu görülmektedir.

Anahtar sözcükler: Helikopter anababalık, özerklik desteği, geçerlik, güvenirlik.

Etik kurul kararı: Bu araştırma, Başkent Üniversitesi Sosyal ve Beşeri Bilimler ve Sanat Arşatırma Kurulu'nun 17.07.2020 tarihli 17162298.600-275 sayılı izniyle yürütülmüştür.

${ }^{1} \mathrm{Bu}$ çalışma, Başkent Üniversitesi Bilimsel Araştırma Projeleri Komisyonu tarafindan desteklenmiştir (Proje no: 34611$)$

${ }^{2}$ Prof. Dr., Eğitim Fakültesi, Eğitim Bilimleri Bölümü, Rehberlik ve Psikolojik Danışmanlık Anabilim Dalı, eposta: figencok@ baskent.edu.tr, https://orcid.org/0000-0003-2406-1345

${ }^{3}$ Arş. Gör., Eğitim Fakültesi, Eğitim Bilimleri Bölümü, Rehberlik ve Psikolojik Danışmanlık Anabilim Dalı, e-posta: chozdemir@baskent.edu.tr, https://orcid.org/0000-0002-8262-2676

${ }^{4}$ Arş. Gör., Eğitim Fakültesi, Eğitim Bilimleri Bölümü, Rehberlik ve Psikolojik Danışmanlık Anabilim Dalı, e-posta: hkozdogan@ baskent.edu.tr, https://orcid.org/0000-0003-4905-7123

${ }^{5}$ Sorumlu Yazar: Arş Gör., Eğitim Fakültesi, Eğitim Bilimleri Bölümü, Rehberlik ve Psikolojik Danışmanlık Anabilim Dal, e-posta: semihtopuz@ baskent.edu.tr, https://orcid.org/0000-0003-1398-4507 
Helikopter anababalık, değişen dünyanın yeni anababalık tipi olarak karşımıza çıkmaktadır. Günümüzde çocuklar geçmiş kuşaklara göre bazı farklılıklarla büyümektedir. Bunlar arasında teknolojik gelişmeler (örneğin cep telefonlarının yaygınlaşması) anababaların çocuklarını sürekli olarak izlemelerine olanak sağlamakta ve çocuklarının yaşamlarına katılımlarını ve müdahale etmelerini değiştirmektedir (Fidan ve Seferoğlu, 2020).

Helikopter anababalık kavramından ilk kez Ginott'un (akt. Hind, 2016) "Anababalar ve Ergenler" kitabında söz edilmiş, ilk tanımlanması ise Cline ve Fay (1990) tarafından yapılmıştır. Helikopter anababalar destek ve koruma sağlamak amacıyla sürekli olarak çocuğunun etrafinda dönüp duran anababalar olarak tanımlanmıştır (Hirsch ve Goldberger, 2010). Helikopter anababalık çocuğun yaşı ile uyumsuz, aşırı ve sürekli korumacı, bireyin özerkliğini kısıtlayan, çocukla ilgili sürekli bilgi arayan ve müdahale davranışlarından oluşan bir anababalık olarak nitelendirilmektedir (Rote ve diğ., 2020).

Yapılan çalışmalar helikopter anababaların bazı ayırt edici özellikleri olduğunu ortaya koymuştur. Çocuklarının yaşamlarına sürekli ve aşırı katılım göstermek, çocuğunun karar verme ve sorun çözmesi durumlarında aşırı kaygılı olmak, çocuğunun yaşantısına sürekli müdahale etmek ve yönetmek, helikopter anababaların genel özellikleri olarak belirtilmiştir (LeMoyne ve Buchanan, 2011). Ayrıca çocuklarını sürekli olarak yaşamlarının odağında tutmak, çocuklarından sürekli başarı beklemek ve onun adına akademik ve sosyal programlar düzenlemek helikopter anababalıkta karşılaşılan davranışlar arasında görülmektedir (Ashton-James ve diğ., 2013). Helikopter anababalar çocuklarının herhangi bir olumsuz yaşantı ve duygu yaşamalarını istememekte ve çocuklarına sorunsuz bir yaşam sunmaya çalışmaktadırlar (Cline ve Fay, 1990). Bu davranışlar çocuğun iyilik durumumun artması, çocuğun sorunlardan uzak kalması gibi olumlu amaçlarla yapılsa da (Rote ve diğ., 2020) helikopter anababaların çocuklarının yaşamın gerçeklik ve zorluklarına karşı savunmasız olmalarına neden olabilmektedir.

Helikopter anababalar çocuklarının yaşamlarını kendilerinin temel ilgi odağı olarak görmektedir (Odenweller ve diğ., 2014). Sürekli olarak çocuklarının mutluluğu ile meşgul olmak ve çocuklarını olumsuz sonuçlardan koruma amacıyla önerilerde bulunarak yönlendirmek helikopter anababalığın tipik davranışları arasında yer almaktadır (Segrin ve diğ., 2012). Helikopter anababaların çocuğun iyiliği üzerinden ortaya koyduğu temel olarak iyi niyetli davranış ve tutumlar (yani çocuğun yaşamını kolaylaştırmak ya da olumsuzluklardan uzak tutmak amacıyla ortaya çıkan kısıtlama, müdahale vb. davranışlar) çocukların gelişim sürecinde beklenmeyen bazı olumsuz sonuçları beraberinde getirebilmektedir. Helikopter anababalar çocukları üzerinde destekleyici oldukları yönünde bir duygu yaratmaktadır (Darlow ve diğ., 2017). Ancak araştırmalarca ortaya konan yoğun olumsuz sonuçlar bu tür anababalığın nedenlerinin ve çocuklar ile gençler üzerindeki etkilerinin incelenmesi giderek artan ölçüde önem kazanmaktadır. 
Helikopter anababaların amacı çocuklarını olası olumsuz yaşantı ve risklerden uzak tutmak olsa da davranışları çocuklarının bağlanma (McGinley, 2018), nevrotizm (Montgomery, 2010), depresyon (Hong ve Doh, 2018), düşük başa çıkma becerileri (McGinley, 2018) ve sosyal uyum zorlukları (Darlow ve diğ., 2017) gibi sosyal ve okul tükenmişliği (Love ve diğ., 2020) gibi akademik sorunlara yol açabilmektedir.

Helikopter anababalığın etkileri üniversiteye geçiş yapmış gençlerde de görülmektedir. Üniversite dönemindeki gençlerin bağımsızlık gereksinimin arttığı ve anababalar tarafından özerkliğin kısıtlanmasının gençlerde davranışsal ve duygusal olumsuz sonuçlara yol açabildiği belirtilmiştir (Padilla-Walker ve Nelson, 2012). Helikopter anababalıkta çok yaygın olan anababa kontrolünün Öz Belirleme Kuramı çerçevesinde özerklik, yetkinlik ve ilişkili olma olarak belirlenmiş temel psikolojik ihtiyaçları olumsuz etkileyebileceği belirtilmiştir (Deci ve Ryan, 2008; Ryan ve Deci, 2000; Soenens ve Vansteenkiste, 2010). Anababa kontrolü çocukların özerklik ve yeterlilik duygularını olumsuz etkilemekte ve anababayla ilişkisine zarar verebilmektedir (Schiffrin ve diğ., 2014). Ayrıca psikolojik kontrolün üniversite öğrencilerinin psikolojik iyi oluşlarını olumsuz etkilediğini bildiren çalışmalar da vardır (LeMoyne ve Buchanan, 2011).

Üniversite öğrencilerinin bakış açısından helikopter anababalığı incelemek amacıyla geliştirilmiş farklı ölçme araçları bulunmaktadır. LeMoyne ve Buchanan (2011) üniversite öğrencilerinin algıladıkları helikopter anababalığı incelemek amacıyla tek boyutlu bir ölçek olan Helikopter Anne-Babalık Ölçeği'ni geliştirmişlerdir. Padilla-Walker ve Nelson (2012) tarafından geliştirilen Helicopter Parenting Scale anababaların genç yetişkin çocukları yerine önemli kararlar almaları çerçevesinde geliştirilmiştir. Bir başka çalışmada Y kuşağı tarafindan algılanan ve gelişimsel olarak uygun olmayan helikopter anababalık davranışlarını incelemek amaciyla Odenweller ve diğ. (2014) tarafindan Helikopter Ebeveynlik Ölçeği (Helicopter Parenting Instrument [HPI]) geliştirilmiştir. Ayrıca Hind (2016) geliştirdiği Helicopter Parent Controlling Item ile anababaların güncel davranışlarını temel alarak helikopter anababalık davranışları ve anababa katılımına odaklanmıştır. Geliştirilen ölçme araçlarının genel olarak anababaların kontrol ve katılım boyutuna odaklandığı görülmektedir.

Anababalık kontrolünün tersine, özerklik destekleyici davranışlar çocuğun gelişim sürecinde karar verme becerisi (Grolnick ve diğ., 1991), yüksek sosyal ve duygusal uyum (Kenney-Benson ve Pomerantz, 2005) gibi önemli yararlar sağlamaktadır. Özerklik desteği üniversite öğrencilerinde kaygı ve depresyon ile olumsuz, yaşam doyumu ile olumlu ilişkili olarak bulunmuştur (Reed ve diğ., 2016). Ayrıca özerklik Öz Belirleme Kuramı'na göre, psikolojik iyi oluş için temel psikolojik ihtiyaçlardan biri olarak görülmektedir (Deci ve Ryan, 2008; Ryan ve Deci, 2000). Bu çalışmada diğer çalışmalara göre helikopter anababalık özerklik ile bağlantılı incelenerek konuya daha geniş bir bakış açısı sağlanmaktadır. Schiffrin ve diğ. (2014) tarafından geliştirilen Helikopter Anababalık ve Özerklik Destekleyici Davranışlar (HAÖDD) Ölçeği, Öz Belirleme Kuramına (Self Determination Theory) dayalı 
olarak, özerklik destekleyici davranışlar ile helikopter anababalık davranışlarını birlikte incelemekte, bu yönüyle geliştirilen diğer ölçeklerden ayrılmaktadır.

Helikopter Anababalık ve Özerklik Destekleyici Davranışlar Ölçeği'nin farklı ülkelerde kullanıldığı ve farklı değişkenlerle birlikte ele alındığı görülmektedir. Ölçek Koreli gençlerle yapılan ölçek geliştirme çalışmasında kullanılmıştır (Chae ve diğ., 2016). Ayrıca ölçek, ABD'li gençlerin helikopter anababalığın anababalık kaygısı ve gençlerin psiko-sosyal sorunlarına (depresyon, kaygı ve duygu düzensizliği) etkisini incelemek (Cui ve diğ., 2019), helikopter anababalık ve özerklik desteğinin gençlerin algıladığı akademik kontrol ile ilişkisini incelemek (Hwang ve Jung, 2020), ABD’li ve Güney Koreli gençlerin helikopter anababalık, özerklik desteği, fiziksel sağlık ve yaşam doyumunu incelemek için (Jung ve diğ., 2020), farklı etnik kökene sahip gençlerin helikopter anababalık, özerklik desteği ile üniversite öğrencilerinin ruh sağlığı ve iyi oluşlarına etkisini incelemek için kullanılmıştır (Kouros ve diğ., 2017). Ayrıca ölçek özerklik desteği ile temel psikolojik gereksinimler ve internet bağımlılığı ilişkisini incelemek için de kullanılmıştır (Liu ve diğ., 2021). Yapılan çalışmalar incelendiğinde, ölçeğin son yıllarda gençlerin gelişimini çeșitli değișkenlerle birlikte ele alarak helikopter anababalık konusundaki bilgi birikimine katkıda bulunmak için araştırmalarda kullanıldığı görülmektedir.

Helikopter anababalık kavramı Türkçe alanyazına yakın zamanda girmiş olup konuya ilişsin sınırlı sayıda araştırma ve ölçek çalışması bulunmaktadır. Türkiye'de helikopter anababalığı incelemek için Yılmaz (2019) tarafından geliştirilen Algılanan Helikopter Ebeveyn Tutum Ölçeği, Ertuna (2016) tarafindan uyarlanan Helikopter Ebeveynlik Ölçeği ve Okray (2016) tarafından uyarlanan Helikopter Ana-Babalık Ölçeği bulunmaktadır. Ancak Helikopter Anababalık ve Özerklik Destekleyici Davranışlar Ölçeği üniversite öğrencilerinde helikopter anababalık davranışlarının yanında bu davranışların doğrudan etkide bulunduğu özerklik destekleyici davranışların incelenmesine olanak sağlamakta ve bu ana-babalık tipinin davranışsal yapısının daha iyi anlaşılmasına yardımcı olmaktadır. Bu amaçla Türkiye'de yapılacak araştırmalarda kullanılmak üzere, alanyazında sıklıkla kullanılan (Chae ve diğ., 2016; Cui ve diğ., 2019; Hwang ve Jung, 2020; Jung ve diğ., 2020; Kouros ve diğ., 2017). Helikopter Anababalık ve Özerklik Destekleyici Davranışlar Ölçeği’nin Türkçe geçerlik ve güvenirlik çalışmasına gereksinim duyulmaktadır.

Helikopter anababalık davranışları genç yetişkinlik dönemindeki üniversite öğrencilerini akademik, psikolojik ve sosyal açıdan etkilemektedir. Yapılan çalışmalar bu etkinin daha çok olumsuz yönde olduğunu ortaya koymakta ve özellikle psikolojik ve sosyal gelişimlerinde ortaya çıkan olumsuz sonuçlara dikkat çekmektedir (Earle ve LaBrie, 2016; McGinley, 2018; Montgomery, 2010). Üniversite öğrencilerinin algıladığı helikopter anababalık davranışlarının etkilerinin incelenmesinin, gençlerin yetişkinliğe geçiş döneminde yaşadıkları farklı sorunlarını anlamada önemli olduğu düşünülmektedir. Ayrıca üniversite öğrencilerinde helikopter anababalığın ve özerklik destekleyici davranışların incelenmesinin gençlerin yaşam becerileri, istihdam sorunları ve ruh sağlı̆̆ gibi çeşitli konulara katkı 
sağlayacağı düşünülmektedir. Bu amaçla helikopter anababalık davranışları ve özerklik destekleyici davranışları birlikte inceleyen Schiffrin ve di ̌̆ (2014) tarafından geliştirilen Helikopter Anababalık ve Özerklik Destekleyici Davranışlar Ölçeği’nin Türkçeye uyarlanması önemli görülmektedir. Helikopter Anababalık ve Özerklik Destekleyici Davranışlar Ölçeği bu çalışmada Türkçeye uyarlanarak ölçeğin psikometrik özellikleri açısından incelenmesi hedeflenmektedir. Böylelikle araştırma birikimine katkı sağlanacağı düşünülmektedir.

\section{Yöntem}

Bu bölümde çalışma grubu, veri toplama aracı, ölçeği uyarlama süreci, verilerin toplanması ve verilerin analizi konusundaki çalışmalar yer almaktadır.

\section{Çalışma Grubu}

Araştırmanın çalışma grubunu, 2019-2020 öğretim yılı güz yarıyılında Ankara'da bulunan bir vakıf üniversitesinde çeşitli alanlarda öğrenim görmekte olan ikinci ve dördüncü sınıf öğrencileri oluşturmaktadır. Çalışma grubunda beş fakülte ve 13 lisans programından 488 gönüllü öğrenci yer almaktadır. Çalışma grubunun belirlenmesi, ulaşılabilirlik ve elverişlilik esasına göre yapılmıştır. Öğrencilerin kolay ulaşılabilir olması amac1 ile uygun örnekleme (convenience sampling) yöntemi kullanılmıştır (Fraenkel ve Wallen, 2009).

Araştırmaya katılan 488 öğrencinin \%78'ini $(n=381)$ kadınlar, \%22'sini $(n=$ 107) erkekler oluşturmaktadır. Yaşları 18 ile 27 arasında değişmektedir ve yaş ortalamas1 21.25 'tir. 2. sınıf öğrencileri örneklemin \%58'ini $(n=284)$, 4. sinıf öğrencileri ise \%42'sini $(n=204)$ oluşturmaktadır. Çalışma grubunun \%25'ini $(n=$ 121) Güzel Sanatlar Fakültesi, \%11'ini $(n=55)$ İletişim Fakültesi, \%22'sini $(n=106)$ Sağlık Bilimleri Fakültesi, \%31'ini $(n=150)$ Eğitim Fakültesi, \%11'ini $(n=56)$ İktisadi ve İdari Bilimler Fakültesi öğrencileri oluşturmaktadır.

\section{Veri Toplama Aracı}

Araştırmada veri toplama aracı olarak Helikopter Anababalık ve Özerklik Destekleyici Davranışlar Ölçeği kullanılmıştır. Aynı zamanda ölçekle birlikte öğrencilere ait cinsiyet, sınıf düzeyi ve eğitim görülen fakülte bilgileri elde edilmiştir. Araştırmada kullanılan veri toplama aracına ait bilgiler aşağıda sunulmuştur.

\section{Helikopter Anababalık ve Özerklik Destekleyici Davranışlar Ölçeği}

Özgün ölçek üniversite öğrencilerinin algılanan helikopter anababalık davranışlarını incelemek amacıyla Schiffrin ve diğ. (2014) tarafından öz belirleme kuramına dayalı olarak geliştirilmiştir. Helikopter ebeveynlik ve özerklik destekleyici davranışlar ölçeği altılı likert tipinde (1: hiç katılmıyorum; 6: tamamen katıllyorum) toplam 15 maddeden oluşmaktadır. Ölçek, "helikopter anababalık" (HA) ve "özerklik destekleyici davranışlar" (ODD) boyutlarından oluşmaktadır. Helikopter anababalık boyutu dokuz maddeden, özerklik destekleyici davranışlar boyutu ise altı maddeden oluşmaktadır. Helikopter anababalık boyutunda "Annemle evde olduğumda, her akşam eve girmem/gelmem gereken belli bir saat olur." gibi maddeler yer alırken, 
özerklik destekleyici davranışlar boyutu "Annem kendi kararlarımı vermem ve kararlarımın sorumluluğunu almam konusunda beni cesaretlendirir" gibi maddeler içermektedir. Özgün ölçek, anne davranışlarına ilişkin algıları ortaya koyan maddeler içermektedir. Schiffrin ve diğ. (2014), bunun nedenini ilgili alanyazına dayalı olarak, annelerin babalara göre yetişkin çocukların yaşamlarına oldukça fazla dahil oldukları biçiminde belirtmektedir (Schiffrin ve diğ., 2014).

Özgün ölçek çalışması 297 üniversite öğrencisiyle gerçekleştirilmiştir. Ölçeğin uygulandığ 1 örneklemin \%18'i erkek, \%88'i kadın öğrencilerden oluşturmaktadır. Ölçeğin geliştirilme aşamasında yapılan açımlayıcı faktör analizi sonucunda dokuz maddeden oluşan helikopter anababalık varyansın \%20.77'sini açıklarken, özerklik destekleyici davranışlar varyansın \%9.73'ünü açıklamaktadır. Ölçeğin güvenirliğine ilişkin yapılan analiz sonucunda elde edilen iç tutarlılık katsayıları helikopter anababalık için .77, özerklik destekleyici davranışlar için .71 olarak bulunmuştur (Schiffrin ve diğ., 2014). Bir diğer çalışmada özgün ölçeğe benzer şekilde iç tutarlık katsayısı helikopter anababalık için .82; özerklik destekleyici davranışlar için .78 olarak bulunmuştur (Reed ve diğ., 2016). Bu bulgular genel olarak özgün ölçeğin geliştirildiği kültürde geçerli ve güvenilir olduğunu göstermektedir.

\section{Ölçeği Uyarlama Süreci}

Özgün ölçeği geliştiren araştırmacılardan gerekli izinler alındıktan sonra Uluslararası Test Komisyonu'nun (International Test Commision [ITC]) önerdiği ölçek uyarlama süreçleri izlenerek uyarlama çalışmasına başlanmıştır. Ölçeğin uyarlama sürecinde çeviri-geri çeviri yöntemi kullanılmıştır. Ölçek ilk aşamada alan ve dil yeterliğine sahip üç uzman tarafından Türkçeye çevrilmiş, üç kişiden alınan ve karşılaştırılan çeviriler sonrasında maddeler tek bir biçimde bir araya getirilmiştir. Çeviri çalışmasında Türkiye'de yaşayan gençlere uygunluk ve dilsel farklılıklar göz önünde bulundurularak maddeler anlamsal olarak düzenlenmiştir (ITC, 2018). Geri çeviri aşaması için Türkçeye çevrilmiş maddeler üç farklı dil uzmanına İngilizceye çevrilmek üzere iletilmiştir. Ardından son düzenlemeler ile gönüllülük esasına dayanan ön deneme uygulamasına başlanmıştır. Ön deneme uygulamasına katılan öğrencilerden maddelerin açıklık, anlaşılırlık ve anlam özellikleri ile ilgili geri bildirim alınmış ve anlaşılırlık ile dile uygunluk açısından ufak değişiklikler gerçekleştirilmiştir. Ön çalışma sonrası ölçeğe son şekli verilerek ölçeğin geçerlik ve güvenirlik çalışması için 488 öğrenci ile asıl uygulama gerçekleştirilmiştir. Uyarlama çalışması yapılan HAÖDD, üniversite öğrencilerinin algıladıkları helikopter anababalık davranışlarını ve özerklik destekleyici davranışlarını incelemektedir.

\section{Verilerin Toplanması}

Çalışmanın başlangıcında öncelikle araştırmacıların bağlı bulunduğu üniversitenin Etik Kuruluna etik kurul izni için başvurulmuş ve izin alınmıştır. Ardından verilerin toplanacağı fakültelerden gerekli izinler alınmış ve veri toplama süreci planlanmıştır. Uyarlama sürecinin ardından son biçimine getirilen ölçek ile veriler, beş farklı fakülte ve 13 farklı lisans programında öğrenim görmekte olan 488 öğrenciden gönüllülük esasına dayalı olarak toplanmıştır. Ders saatlerinde dersi veren 
öğretim elemanlarının iş birliği ile veri toplama süreci gerçekleştirilmiştir. Veri toplama sırasında öğrenciler çalışmanın amacı hakkında bilgilendirilmiş ve yönerge açıklanmıştır. Çalışmaya katılımın gönüllü olduğu belirtilmiş ve katılmak isteyenlerin gönüllü katılım ile onam kısımlarını işaretlemeleri hatırlatılmıştır. Ardından ölçek öğrencilere uygulanmıştır.

\section{Verilerin Analizi}

Araştırmada, Helikopter Anababalık ve Özerklik Destekleyici Davranışlar Ölçeği’nin psikometrik özelliklerinin incelenmesi amacıyla veriler analiz edilmiştir. $\mathrm{Bu}$ amaç doğrultusunda, uyarlanmış maddelerin, ölçeğin özgün faktör yapısına uygunluğunu test etmek için Doğrulayıcı Faktör Analizi (DFA) yapılmıştır. DFA uyum ölçütlerine bakılmış ve modele istatistiksel uygunluğu test edilmiş̧ir. Ardından ilgili ölçümlerin güvenirliğine ilişkin kanıt elde etmek amacıyla Cronbach Alfa $(\alpha)$ iç tutarlılık katsayıları hesaplanmıştır. Maddelerin ölçeği temsil güçlerinin ölçülmesi amacıyla alt boyut düzeyinde madde-toplam korelasyonları hesaplanmıştır. Daha sonra madde ayırt ediciliklerine kanıt sunmak amaciyla üst ve alt \%27'lik grupların ortalamaları alt boyutlara göre karşılaştırılmıştır. Verilerin analizi için JASP V0.14 paket programı kullanılmıştır.

\section{Bulgular}

Helikopter Anababalık ve Özerklik Destekleyici Davranışlar Ölçeği’nin Türkçe formunun geçerlik ve güvenirliğini test etmek amacıyla yapılan istatistiksel analizlerin sonuçları bu başlıkta verilmiştir.

\section{Doğrulayıcı Faktör Analizi}

İlk olarak doğrulayıcı faktör analizinin sayıltılarını sorgulamak için aşağıda belirtilen analizler yapılmıştır. Analize başlamadan önce kayıp veri kontrolü yapılmış ve 488 yanıttan satır bazında boş olduğu için silinen 12 ve kayıp veri oranı \%5'in altında kaldığ 1 için liste bazında silme yöntemiyle silinen 28 satır ile birlikte 448 yanıtla analize devam edilmiştir (Büyüköztürk ve diğ., 2018; Mertler ve Reinhart, 2017). 448 yanıttan oluşan veri setinin çok değişkenli normal dağılımını incelemek amacıyla Mardia testi yapılmış ve veri setinin çok değişkenli normal dağılım sağlamadığı görülmüşsür. Cook's ve Mahalanobis değerleri göz önünde bulundurularak veri setinin uç değerleri temizlenmiştir. Bu durumda analize 442 veri ile devam edilmiştir. Bunun yanında ZPRED-ZRESID saçılım grafiği kontrol edilmiş ve eş-varyanslılık varsayımının sağlandığı görülmüştür. Madde puanları arasındaki korelasyon katsayıları kontrol edilmiş ve .80 'den büyük korelasyon olmadığ 1 görülmüştür. Bunun yanında varyans şişme oranları (Variance Inflation Factor [VIF]) değerleri incelenmiş ve değerlerin 10'dan küçük olduğu görülmüştür (Kline, 2011). Bu sonuçlar, çoklu bağlantı sorunun olmadığını gösterir niteliktedir. Sayıltıların test edilmesinin ardından doğrulayıcı faktör analizine başlanmıştır.

Özgün ölçekte tanımlanmış iki boyut olan HA ve ODD test edilmesi amacıyla 15 madde analize alınmıştır. Bu durumda madde $1,3,4,7,9,10,11,13$ ve 14 helikopter anababalık, madde 2, 5, 6, 8, 12 ve 15 özerklik destekleyici davranışlar 
faktöründe yer almıştır $\left(\chi^{2}=244.35, \mathrm{df}=89, \chi^{2} / \mathrm{df}=2.75, p<.001, \mathrm{RMSEA}=.062\right.$, $\mathrm{SRMR}=.073, \mathrm{CFI}=.95, \mathrm{NNFI}=.95, \mathrm{NFI}=.93, \mathrm{GFI}=.96)$. Analiz sonucunda önerilen modifikasyonlar incelenmiş ve öneriler doğrultusunda madde 4 ile madde 7 ve madde 5 ile madde 12'nin hata kovaryansları eşleştirilmiştir. Her iki modifikasyon da aynı boyutta yer alan ve benzer süreçleri ölçtüğü düşünülen maddeler üzerinde gerçekleştirilmiştir. Modifikasyonların $\chi^{2}$ 'ye anlamlı katkı sağladığı belirlenmiştir. Analiz sonucunda elde edilen DFA modeli Şekil 1'de sunulmuştur.

Uyum ölçütleri; veri setinin, DFA sonucunda, kuramsal model ile uyumunun değerlendirilebileceği istatistiksel değerlerdir. Alanyazında uyum ölçütleri ile ilgili farklı görüşler yer almaktadır. Uyum ölçütleri için farklı kaynaklardan elde edilmiş değerler Tablo 1'de verilmiştir (Büyüköztürk ve diğ., 2018; Kline, 2011; Tabachnick ve Fidell, 2013).

\section{Tablo 1}

Uyum Ölçütleri

\begin{tabular}{crrr}
\hline Ölçüt & İyi uyum & Mükemmel uyum & Model değeri \\
\hline$\chi 2 / \mathrm{df}$ & $3 \geq \chi^{2} / \mathrm{df} \geq 2$ & $2 \geq \chi^{2} / \mathrm{df}$ & 2.56 \\
RMSEA & $.08 \geq \mathrm{RMSEA} \geq .05$ & $.05 \geq \mathrm{RMSEA}$ & .060 \\
SRMR & $.08 \geq$ SRMR $\geq .05$ & $.05 \geq \mathrm{SRMR}$ & .070 \\
CFI & $.95 \geq \mathrm{CFI} \geq .90$ & $\mathrm{CFI} \geq .95$ & .97 \\
GFI & $.95 \geq \mathrm{GFI} \geq .90$ & $\mathrm{GFI} \geq .95$ & .98 \\
NFI & $.95 \geq \mathrm{NFI} \geq .90$ & $\mathrm{NFI} \geq .95$ & .95 \\
NNFI & $.95 \geq \mathrm{NNFI} \geq .90$ & $\mathrm{NNFI} \geq .95$ & .96 \\
\hline
\end{tabular}

Tablo 1'de yer alan bilgilerden hareket edilerek elde edilen modelin uyum ölçütleri incelendiğinde, iyi uyuma işaret ettiği gözlenmiş̧tir $\left(\chi^{2}=223.02\right.$, df $=87$, $\chi^{2} / \mathrm{df}=2.56, p<.001, \mathrm{RMSEA}=.060, \mathrm{SRMR}=.070, \mathrm{CFI}=.97, \mathrm{NNFI}=.96, \mathrm{NFI}=$ .95 , GFI = .98). Analiz sonucunda elde edilen Şekil 1'de yer alan faktör yükleri incelendiğinde .32 ile .74 arasında değiştiği gözlemlenmiştir. Ölçüm hatası değerleri ise .45 ile .90 arasında değişmektedir. Uyum ölçütleri ve Şekil 1'de sunulan standartlaştırılmış faktör yükleri ve hata değerleri göz önüne alındığında, doğrulayıcı faktör analizi sonucunda, ölçeğin maddelerinin ölçülen faktörlerin uygun bir temsilcisi olduğunu söylemek olanaklıdır. 


\section{Şekil 1}

Doğrulayıcı Faktör Analizi Modeli (Standart Dĕgerler ile)

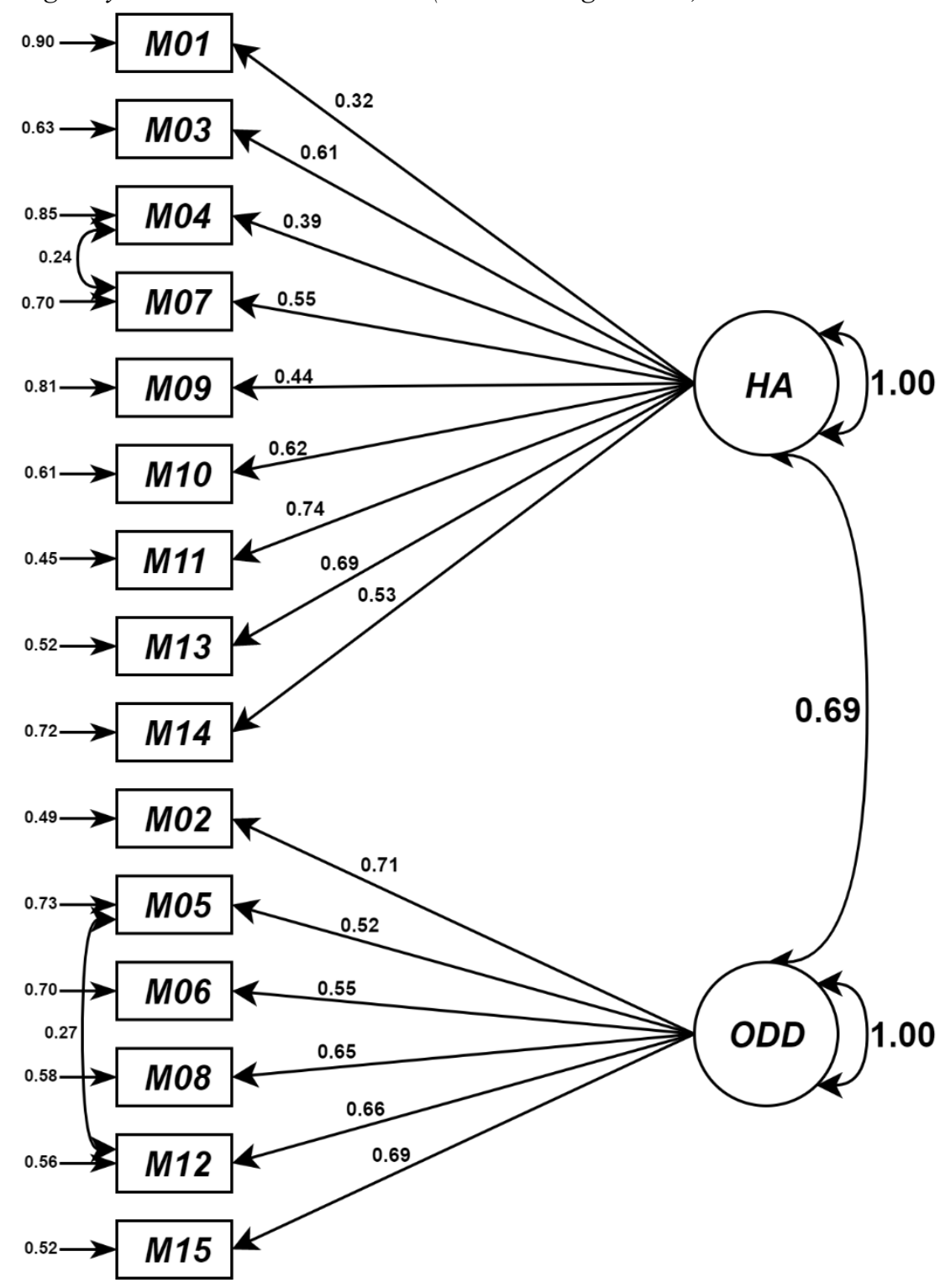




\section{İç Tutarlılık}

Ölçeğin güvenirliğine ilişkin kanıt elde etmek amacıyla Cronbach Alfa iç tutarlılık katsayıları incelenmiştir. Ölçekten elde edilen Cronbach Alfa katsayıları alt boyutlar düzeyinde Tablo 2'de sunulmuştur.

\section{Tablo 2}

Ölçümlere İlişkin Güvenirlik Değerleri

\begin{tabular}{llr}
\hline Boyutlar & $(\alpha)$ & Özgün Ölçek $(\alpha)$ \\
\hline Helikopter Anababalık & .80 & .77 \\
Özerklik Destekleyici Davranışlar & .80 & .71 \\
\hline
\end{tabular}

Tablo 2 incelendiğinde güvenirlik değerlerinin özgün ölçeğe göre yüksek olduğu görülmektedir. Güvenirlik değerleri incelendiğinde, elde edilen alfa değerlerinin kabul edilebilir düzeyin üzerinde olduğu görülmektedir (Nunnally ve Bernstein, 1994). Bu değerlerden hareket ederek Türkçeye uyarlanmış ölçekte iç tutarlılık güvenilirliğinin yüksek olduğu söylenebilir.

\section{Madde Analizleri}

Ölçek maddelerinin alt ölçek toplam puanlarını yordamasına ilişkin elde edilen madde-toplam korelasyon değerleri Tablo 3'te verilmiştir. Bununla birlikte maddelerin ayırt ediciliklerine ilişkin elde edilmiş alt ve üst \%27'lik grup ortalamalarının t testi sonuçları da Tablo 3'te sunulmuştur.

Tablo 3

Madde Analizleri

\begin{tabular}{lrrr}
\hline Faktör Ad1 & Madde & Madde-Toplam & t (üst-alt \%27) \\
\hline & M01 & .31 & $9.65^{*}$ \\
& M03 & .45 & $14.37^{*}$ \\
& M04 & .37 & $10.64^{*}$ \\
Helikopter Anababalık & M07 & .52 & $18.01^{*}$ \\
& M09 & .45 & $10.69^{*}$ \\
& M10 & .55 & $16.68^{*}$ \\
& M11 & .64 & $20.62^{*}$ \\
& M13 & .56 & $18.48^{*}$ \\
& M14 & .55 & $16.45^{*}$ \\
\hline \multirow{3}{*}{ Özerklik Destekleyici } & M02 & .55 & $23.26^{*}$ \\
Davranışlar & M05 & .45 & $14.62^{*}$ \\
& M06 & .62 & $18.45^{*}$ \\
& M08 & .64 & $20.26^{*}$ \\
& M12 & .63 & $18.78^{*}$ \\
\hline Mot. & M15 & .55 & $22.33^{*}$ \\
\hline
\end{tabular}

Not. $\mathrm{n}_{\text {madde-toplam }}=442, \mathrm{n}_{\text {üst-alt } \% 27}=238$

$* p<.01$ 
Tablo 3 incelendiğinde madde toplam korelasyonlarının .31-.64 arasında değiştiği görülmektedir. Ölçek maddelerinin alt ölçek toplam puanlarını yordamada yeterli olduğu söylenebilir (Büyüköztürk, 2020). Bununla birlikte tüm maddeler için üst ve alt \%27'lik grup ortalamaları arasındaki fark istatistiksel olarak anlamlı bulunmuştur. Bu anlamlı fark ölçek maddelerinin ayırt ediciliğine ilişkin kanıt olarak ele alınmıştır. Elde edilen bulgular doğrultusunda, uyarlanmış ölçeğin geçerliği ve güvenirliğine ilişkin değerlerin yeterli olduğu görülmektedir.

\section{Tartışma, Sonuç ve Öneriler}

$\mathrm{Bu}$ çalışmada, Schiffrin ve diğ. (2014) tarafindan geliştirilen, üniversite öğrencilerinin helikopter anababalık ve özerklik destekleyici davranış algılarını ölçen Türkçeye uyarlanmış HAÖDD Ölçeği'nin geçerlik ve güvenirliği incelenmiştir. Özgün ölçekte yer alan tüm maddeler kullanılarak uyarlama çalışması yapılmıştır. Uyarlanmış ölçeğin geçerliğine kanıt elde etmek amacıyla yapılan doğrulayıcı faktör analizinde, özgün ölçekte tanımlanan faktör yapısı test edilmiştir. Elde edilen uyum ölçütleri, faktör yükleri ve hata değerleri göz önüne alınarak ölçeğin tanımlanan faktör yapısında iyi uyum gösterdiği belirlenmiştir. Güvenirlik kanıtları elde etmek amacıyla yapılan analizde, Helikopter Anababalık için özgün ölçekte .77 olarak bulunan Alfa değeri, Türkçe ölçekte .80 olarak bulunmuştur. Özerklik Destekleyici Davranışlar alt boyutunda özgün ölçekte Alfa .71 bulunurken, Türkçe ölçekte .80 olarak bulunmuştur. Bu değerler ölçeğin Türkçe ölçeğin güvenilir ölçümler yapacağına ilişkin bir kanıt olarak ele alınmıştır. Madde analizlerine bakıldığında; madde-toplam korelasyonlarının .31 ile .64 arasında değiştiği görülmektedir. Bu değerlere bakılarak maddelerin ölçeği temsil etme gücünün yeterli olduğu söylenebilir (Büyüköztürk, 2020). Diğer bir madde analizi olan üst-alt \%27'lik grupların ortalamaları arasındaki karşılaştırmada tüm maddeler için istatistiksel olarak anlamlı fark ortaya çıkmıştır. Bu fark, maddelerin ayırt ediciliklerine işaret etmektedir. Sonuç olarak ölçeğin Türkçeye uyarlanmış ölçeğin geçerliği ve güvenirliğine ilişkin kanıtlarla birlikte, üniversite öğrencilerinin perspektifinden helikopter anababalık ve özerklik destekleyici davranış düzeylerini ölçmek amacıyla kullanılabileceği görülmüştür.

Helikopter anababablık olgusu günümüz gençlerini oldukça etkileyen davranışları içeren güncel bir konudur. Çalışmanın bulgularında ölçeğin geçerlik ve güvenirlik çalışmalarının uygun bulunması konunun Türkiye'de çeşitli boyutlarda incelenmesine olanak tanıyacaktır. Örneğin Schiffrin ve diğ. (2014) helikopter anababalığın yüksek depresyon ve düşük yaşam doyumunu yordadığına ve bu ilişkilerin düşük özerklik ve yeterlik ile açıklandığına vurgu yapmışlardır. Dolayısıyla benzer bağlantıların Türkiye'deki gençler üzerinde olup olmadığının incelenmesi gençlerin ve genç aile ilişkilerinin anlaşılması açısından önemlidir. Genel olarak, özerklik desteğinin sağlandığ 1 anababalık davranışlarının çocukların ve gençlerin psikolojik ve sosyal gelişimleri için önemli olduğu söylenebilir. Çocuklarının yaşlarına ve gelişim dönemlerine uygun anababa davranışlarına ve özerklik destekleyici davranışlara yönelik farkındalık sağlayacak anababa eğitimlerinin helikopter anababalık davranışlarını azaltma ve önleme süreçlerinde etkili olacağı beklenmektedir. 
Anababaların çocuklarının gereksinimlerini belirleme ve karşılama becerileri, gelişimsel sonuçları belirlemede anahtar olarak görülmektedir (Grolnick ve Ryan, 1989). Bu beceriler üniversite dönemindeki çocukları için de önemini korumaya devam etmektedir (Schiffrin ve diğ., 2014). Helikopter anababalık ve özerklik destekleyici davranışların yetişkinliğe geçiş sürecinde, gençlerin yetişkin rol ve sorumluluklarına hazırlanmalarında etkili olduğu ve bu nedenle incelenmesinin önemli olduğu düşünülmektedir.

Anababaların yetişkinliğe geçiş dönemindeki çocuklarında devam eden helikopter anababalık davranışlarının olumsuz akademik, sosyal ve psikolojik sonuçları olduğu bilinmektedir. Ancak bu çalışmada ele alınan ölçeğin daha sonraki çalışmalarda helikopter anababalığın gençler üzerindeki etkilerine yoğunlaşılarak kullanılması ile bir bilgi birikimine ulaşılacağı beklenmektedir. Çalışmanın uzun vadeli doğurgusu olarak anababa eğitimlerinin gelişmesi ve hem anababalarda hem de gençlerde helikopter anababalık davranışlarına yönelik farkındalık sağlayacak eğitim içeriklerin hazırlanması önerilebilir.

Ölçeğin geçerlik ve güvenirlik kanıtlarının yanında, kuşkusuz bu çalışmanın bazı sınırlılıkları bulunmaktadır. Ölçeğin özgün maddelerine bağlı kalınarak yalnızca anne davranışına yönelik algının değerlendirilmesi bir sınırlılık olarak belirtilebilir. Öte yandan, annelerin daha çok helikopter anababa davranışı sergilediğini gösteren çalışmalar bulunmaktadır (Fingerman ve diğ., 2012; Rousseau ve Scharf, 2015). Çalışmanın daha büyük ve seçkisiz bir örneklemle tekrarlanması, Türkçeye uyarlanmış ölçeğin temellerini sağlamlaştıracaktır. Ayrıca helikopter anababalık davranışının, öncelikle orta ve üst-orta sosyoekonomik düzeye sahip örneklemle ilişkili olduğu ve farklı sosyoekonomik düzeylerde ölçümleri için daha fazla çalışmaya gereksinim olduğu bilinmektedir (Schiffrin ve diğ., 2014). Ayrıca helikopter anababalık ve özerklik destekleyici davranışların hem gençlerde hem de davranışları gösteren anababalarda öz yeterlilik, kaygı, depresyon, yaşam doyumu ve fiziksel sağlık gibi değişkenlerle birlikte değerlendirilmesi yararlı olacaktır (Reed ve diğ., 2016). Ölçeğin farklı eğitim ortamlarında eğitimlerine devam eden, eğitimlerine devam etmeyen ve farklı bölgelerde yaşayan gençler üzerinde çalışılması da ölçeğin gücünün arttırılması açısından önemli görünmektedir. Çalışma grubunun büyük bölümünü kadın katılımcıların oluşturması çalışmanın bir sınırlılığı olarak ele alınabilir. Yapılacak çalışmalarda kadın ve erkek katılımcı sayılarının yakın olması, kavramın yaygınlığı ve kapsayıcılığın hakkında bilgi sağlayacaktır. Daha sonraki çalışmalarda, ölçeğin geçerliğini sağlamlaştıracak ölçme değişmezliği çalışmaları yapılabilir. Bunlara ek olarak bu çalışmada araştırma grubunun iki ve dördüncü sınıf öğrencileri ile sınırlandırılmasına gidilmiştir. Gelecek çalışmalarda sınıf düzeyi de dahil olmak üzere daha temsil edici genç gruplarında çalışılması uygun olacaktır. Yine gelecek çalışmalarda, örneklemenin ana-baba birliktelik durumu, ana-babanın sağ ya da vefat etmiş olma durumları gibi değişkenlerle tabakalandırılarak yapılması ölçeğin geçerliğini sağlamlaştırabilir. Bu çalışmada, ölçeğin özgün faktör yapısına uygunluğu test edilmiştir. Ölçeğin geçerliğine katkı sağlayacak çalışmalar alanyazın bulgularına dayalı olarak çeşitlendirilebilir. 


\section{Kaynakça}

Ashton-James, C. E., Kushlev, K., and Dunn, E. W. (2013). Parents reap what they sow: Child-centrism and parental well-being. Social Psychological and Personality Science, 4(6), 635-642. https://doi.org/10.1177/1948550613479804

Büyüköztürk, Ş. (2020). Sosyal bilimler için veri analizi el kitabı: Istatistik, araştırma deseni SPSS uygulamalarl ve yorum. Pegem Akademi.

Büyüköztürk, Ş., Şekercioğlu, G. ve Çokluk, Ö. (2018). Sosyal bilimler için çok değişkenli istatistik: SPSS ve Lisrel uygulamaları (5. Basım). PEGEM Akademi.

Chae, M. O., Yim, S. Y., Lee, Y. H., Kim, J. H., and Oh, J. (2016). Reliability and validity of the Korean version of the helicopter parenting scale. Child Health Nursing Research, 22(3), 207-214. https://doi.org/10.4094/chnr.2016.22.3.207

Cline, F. W., and Fay, J. (1990). Parenting with love and logic: Teaching children responsibility. Pinon Press.

Cui, M., Darling, C. A., Coccia, C., Fincham, F. D., and May, R. W. (2019). Indulgent parenting, helicopter parenting, and well-being of parents and emerging adults. Journal of Child and Family Studies, 28(3), 860-871. https://doi.org/10.1007/s10826-018-01314-3

Darlow, V., Norvilitis, J. M., and Schuetze, P. (2017). The relationship between helicopter parenting and adjustment to college. Journal of Child and Family Studies, 26(8), 2291-2298. https://doi.org/10.1007/s10826-017-0751-3

Deci, E. L., and Ryan, R. M. (2008). Self-determination theory: A macrotheory of human motivation, development, and health. Canadian Psychology/Psychologie Canadienne, 49(3), 182-185. https://doi.org/10.1037/a0012801

Earle, A. M., and LaBrie, J. W. (2016). The upside of helicopter parenting: Engaging parents to reduce first-year student drinking. Journal of Student Affairs Research and Practice, 53(3), 319-330. https://doi.org/10.1080/19496591.2016.1165108

Ertuna, E. (2016). The Turkish translation, and reliability, validity study of helicopter parenting instrument [Yüksek lisans tezi, Yakın Doğu Üniversitesi]. http://docs.neu.edu.tr/library/6363339489.pdf

Fidan, A., and Seferoğlu, S. S. (2020). Online environments and digital parenting: An investigation approaches, problems and recommended solutions. Bartın University Journal of Faculty of Education, 9(2), 352-372. https://app.trdizin.gov.tr/publication/paper/detail/TkRVeE16YzJOZz09

Fingerman, K. L., Cheng, Y.-P., Wesselmann, E. D., Zarit, S., Fustenberg, F., and Birditt, K. S. (2012). Helicopter parents and landing pad kids: Intense parental support of grown children. Journal of Marriage and Family, 74(4), 880-896. https://doi.org/10.1111/j.1741-3737.2012.00987.x 
Fraenkel, J. R., and Wallen, N. E. (2009). How to design and evaluate research in education (7th ed.). McGraw-Hill.

Grolnick, W. S., and Ryan, R. M. (1989). Parent styles associated with children's selfregulation and competence in school. Journal of Educational Psychology, 81(2), 143-154. https://doi.org/10.1037/0022-0663.81.2.143

Grolnick, W. S., Ryan, R. M., and Deci, E. L. (1991). Inner resources for school achievement: Motivational mediators of children's perceptions of their parents. Journal of Educational Psychology, 83(4), 508-517. https://doi.org/10.1037/0022-0663.83.4.508

Hind, B. Z. (2016). Conceptualization, measurement, and effects of helicopter parenting on college students from the millennial generation [Doctoral dissertation, Western Michigan University]. http://scholarworks. wmich.edu/cgi/viewcontent.cgi?article=2931\&context=diss ertations

Hirsch, D., and Goldberger, E. (2010). Hovering practices in and outside the classroom. About Campus, 14(6), 30-32. https://doi.org/10.1002/abc.20007

Hong, M.-H., and Doh, H.-S. (2018). Effects of helicopter parenting on depression in female emerging adults: examining the mediating role of adaptive and maladaptive perfectionism. Korean Journal of Child Studies, 39(6), 143-158. https://doi.org/10.5723/kjcs.2018.39.6.143

Hwang, W., and Jung, E. (2020). Parenting practices, parent-child relationship, and perceived academic control in college students. Journal of Adult Development, 28(1), 1-13. https://doi.org/10.1007/s10804-020-09346-0

International Test Commission. (2018). Guidelines for translating and adapting tests. International Journal of Testing, 18(2), 101-134. https://doi.org/10.1080/15305058.2017.1398166

Jung, E., Hwang, W., Kim, S., Sin, H., Zhao, Z., Zhang, Y., and Park, J. H. (2020). Helicopter parenting, autonomy support, and student wellbeing in the United States and South Korea. Journal of Child and Family Studies, 29(2), 358-373. https://doi.org/10.1007/s10826-019-01601-7

Kenney-Benson, G. A., and Pomerantz, E. M. (2005). The role of mothers' use of control in children's perfectionism: Implications for the development of children's depressive symptoms. Journal of Personality, 73(1), 23-46. https://doi.org/10.1111/j.1467-6494.2004.00303.x

Kline, R. B. (2011). Principles and practice of structural equation modeling (3th ed.). The Guilford Press. 
Kouros, C. D., Pruitt, M. M., Ekas, N. V., Kiriaki, R., and Sunderland, M. (2017). Helicopter parenting, autonomy support, and college students' mental health and well-being: The moderating role of sex and ethnicity. Journal of Child and Family Studies, 26(3), 939-949. https://doi.org/10.1007/s10826-016-0614-3

LeMoyne, T., and Buchanan, T. (2011). Does "hovering" matter? Helicopter parenting and its effect on well-being. Sociological Spectrum, 31(4), 399-418. https://doi.org/10.1080/02732173.2011.574038

Liu, D., Wang, Z., Yang, X., Zhang, Y., Zhang, R., and Lin, S. (2021). Perceived autonomy-supportive parenting and internet addiction: respiratory sinus arrhythmia moderated the mediating effect of basic psychological need satisfaction. Current Psychology, 40(9), 1-10. https://doi.org/10.1007/s12144$\underline{019-00485-6}$

Love, H., May, R. W., Cui, M., and Fincham, F. D. (2020). Helicopter parenting, selfcontrol, and school burnout among emerging adults. Journal of Child and Family Studies, 29(2), 327-337. https://doi.org/10.1007/s10826-019-01560-z

McGinley, M. (2018). Can hovering hinder helping? Examining the joint effects of helicopter parenting and attachment on prosocial behaviors and empathy in emerging adults. The Journal of Genetic Psychology, 179(2), 102-115. https://doi.org/10.1080/00221325.2018.1438985

Mertler, C. A., and Reinhart, R. V. (2017). Advanced and multivariate statistical methods: practical application and interpretation (6th ed.). Taylor \& Francis.

Montgomery, N. (2010, May). The negative impact of helicopter parenting on personality. Poster session presented at the Annual Meeting of the Association of Psychological Science, Boston.

Nunnally, J., and Bernstein, I. (1994). Psychometric theory (3th ed.). McGraw-Hill.

Odenweller, K. G., Booth-Butterfield, M., and Weber, K. (2014). Investigating helicopter parenting, family environments, and relational outcomes for millennials. Communication Studies, 65(4), 407-425. https://doi.org/10.1080/10510974.2013.811434

Okray, Z. (2016). Helicopter parenting and related issues: Psychological well being, basic psychological needs and depression on university students. Current $\begin{array}{llll}\text { Research in 2(3), } & \text { 165-173. }\end{array}$ https://atif.sobiad.com/index.jsp?modul=makaledetay\&Alan=sosyal\&Id=AWY IrbdHDbCZb mQzvp

Padilla-Walker, L. M., and Nelson, L. J. (2012). Black hawk down?: Establishing helicopter parenting as a distinct construct from other forms of parental control during emerging adulthood. Journal of Adolescence, 35(5), 1177-1190. https://doi.org/10.1016/j.adolescence.2012.03.007 
Reed, K., Duncan, J. M., Lucier-Greer, M., Fixelle, C., and Ferraro, A. J. (2016). Helicopter parenting and emerging adult self-efficacy: Implications for mental and physical health. Journal of Child and Family Studies, 25(10), 3136-3149. https://doi.org/10.1007/s10826-016-0466-x

Rote, W. M., Olmo, M., Feliscar, L., Jambon, M. M., Ball, C. L., and Smetana, J. G. (2020). Helicopter parenting and perceived overcontrol by emerging adults: A family-level profile analysis. Journal of Child and Family Studies, 29(11), 31533168. https://doi.org/10.1007/s10826-020-01824-z

Rousseau, S., and Scharf, M. (2015). "I will guide you": The indirect link between overparenting and young adults' adjustment. Psychiatry Research, 228(3), 826834. https://doi.org/10.1016/j.psychres.2015.05.016

Ryan, R. M., and Deci, E. L. (2000). Self-determination theory and the facilitation of intrinsic motivation, social development, and well-being. American Psychologist, 55(1), 68-78. https://doi.org/10.1037//0003-066x.55.1.68

Schiffrin, H. H., Liss, M., Miles-McLean, H., Geary, K. A., Erchull, M. J., and Tashner, T. (2014). Helping or hovering? The effects of helicopter parenting on college students' well-being. Journal of Child and Family Studies, 23(3), 548557. https://doi.org/10.1007/s10826-013-9716-3

Segrin, C., Woszidlo, A., Givertz, M., Bauer, A., and Taylor Murphy, M. (2012). The association between overparenting, parent-child communication, and entitlement and adaptive traits in adult children. Family Relations, 61(2), 237252. https://doi.org/10.1111/j.1741-3729.2011.00689.x

Soenens, B., and Vansteenkiste, M. (2010). A theoretical upgrade of the concept of parental psychological control: Proposing new insights on the basis of selfdetermination theory. Developmental Review, 30(1), 74-99. https://doi.org/10.1016/j.dr.2009.11.001

Tabachnick, B. G., and Fidell, L. S. (2013). Using multivariate statistics (6th ed.). Pearson.

Yılmaz, H. (2019). İyi ebeveyn, çocuğu için her zaman her şeyi yapan ebeveyn değildir: Algılanan Helikopter Ebeveyn Tutum Ölçeği (AHETÖ) geliştirme çalışması. Erken Çocukluk Çalışsmaları Dergisi, 3(1), 3-31. https://doi.org/10.24130/eccd-jecs.1967201931114

\section{Etik Kurul Kararı}

Bu araştırma, Başkent Üniversitesi Sosyal ve Beşeri Bilimler ve Sanat Arşatırma Kurulu'nun 17.07.2020 tarihli 17162298.600-275 sayılı izniyle yürütülmüş̧ür. 
Ankara University Journal of Faculty of Educational Sciences

Year: 2022, Volume: 55, Issue: 2, 339-359

DOI: 10.30964/auebfd.886761, E-ISSN: 2458-8342, P-ISSN: 1301-3718

\title{
Adaptation of Helicopter Parenting and Autonomy Supportive Behaviors to Turkish: Validity and Reliability Study ${ }^{1}$
}

\begin{tabular}{cccc}
\hline $\begin{array}{c}\text { ARTICLE TYPE } \\
\text { Research Article }\end{array}$ & $\begin{array}{c}\text { Received Date } \\
02.25 .2021\end{array}$ & $\begin{array}{c}\text { Accepted Date } \\
03.02 .2022\end{array}$ & $\begin{array}{c}\text { Published Date } \\
03.03 .2022\end{array}$ \\
\hline \multirow{4}{*}{ Figen Çok (iD ${ }^{2}$, Cansu Hazal Güçlü (D) ${ }^{3}$, Hatice Kübra Özdoğan (iD } & 4 \\
and Semih Topuz (D) & \\
Başkent University &
\end{tabular}

\begin{abstract}
The aim of this study is to adapt the Helicopter Parenting and Autonomy Supportive Behaviour Scale developed by Schiffrin, Liss, Miles-McLean, Geary, Erchull, and Tashner to Turkish and to examine its validity and reliability. The original form of the scale consists of 15 items and two dimensions: Helicopter Parenting and Autonomy Supportive Behaviours. After communicating with the original authors the translation process the 6-point likert form was administered to 381 (78\%) females, 107 (22\%) males total of 488 university students. Confirmatory factor analysis was conducted to obtain evidence for the validity of the scale. The scale was found to fit well with the two dimensional structure as in the original form $\left(\chi^{2}=\right.$ 223.02, $\mathrm{df}=87, \chi^{2} / \mathrm{df}=2.56, \mathrm{p}<.001, \mathrm{RMSEA}=.060, \mathrm{SRMR}=.070, \mathrm{CFI}=.97, \mathrm{NNFI}=.96$, $\mathrm{NFI}=.95, \mathrm{GFI}=.98$ ). To establish reliability, Cronbach Alpha internal consistency coefficient has been calculated. The Cronbach Alpha coefficient was $\alpha=.80$ for the helicopter parenting dimension and $\alpha=.80$ for the autonomy supportive behaviours dimension. Correlations were found to vary between .31-.64. In all items, a significant difference was found between the means of the upper-lower $27 \%$ groups. The results yield that, Helicopter Parenting and Autonomy Supportive Behaviour Scale consisting of 15 items is a valid and reliable instrument to examine helicopter parenting and autonomy supportive behaviours of parents from the perspective of university students in Turkey.

Keywords: Helicopter parenting, autonomy support, validity, reliability.

Ethical committee approval: This research was conducted with the permission of Baskent University Social and Human Sciences and Art Research Board, dated 17.07.2019 and numbered 17162298.600-275.
\end{abstract}

\footnotetext{
${ }^{1}$ This study was supported by the Baskent University Scientific Research Projects Commission. (Project no: 34611)

${ }^{2}$ Prof. Dr., Faculty of Education, Department of Educational Sciences, Program of Guidance and Psychological Counseling, e-mail: figencok@ baskent.edu.tr, https://orcid.org/0000-0003-2406-1345

${ }^{3}$ Res. Assist., Faculty of Education, Department of Educational Sciences, Program of Guidance and Psychological Counseling, e-mail: chozdemir@ baskent.edu.tr, https://orcid.org/0000-0002-8262-2676 ${ }^{4}$ Res. Assist., Faculty of Education, Department of Educational Sciences, Program of Guidance and Psychological Counseling, e-mail: hkozdogan@ baskent.edu.tr, https://orcid.org/0000-0003-4905-7123 ${ }^{5}$ Corresponding Author: Res. Assist., Faculty of Education, Department of Educational Sciences, Program of Guidance and Psychological Counseling, e-mail: semihtopuz@baskent.edu.tr, https://orcid.org/00000003-1398-4507
} 


\section{Purpose and Significance}

Helicopter parenting is emerging as the new type of parenting in the developing and changing world. Technological developments allow parents to monitor their children continuously and facilitate their participation and intervention in their children's lives. Studies have revealed that helicopter parents have some distinctive features. Continuous and excessive participation in the lives of their children, being excessively anxious in decision-making and problem-solving situations and constantly intervening and managing their child's life are stated as general characteristics of helicopter parents (LeMoyne and Buchanan, 2011). Helicopter parents do not want their children to experience any negative experiences and emotions and try to offer their children a problem-free life (Cline and Fay, 1990). Although these behaviours are for a favourable purpose, helicopter parents can cause their children to be vulnerable to the reality and difficulties of life.

The effects of helicopter parenting are also seen among university students. The need for autonomy increases in university students developmentally and the restriction of autonomy by parents may lead to behavioural and emotional negative consequences for young people (Padilla-Walker and Nelson, 2012).

Parental control, which is very common in helicopter parenting, can negatively affect basic psychological needs, which are determined as autonomy, competence and relatedness within the framework of Self-Determination Theory (Deci and Ryan, 2008; Ryan and Deci, 2000; Soenens and Vansteenkiste 2010). Parental control negatively affects children's feelings of autonomy and competence and damages their relationship with parents (Shiffrin et al., 2014). In contrast to parental control, autonomy-supporting behaviours provide significant benefits such as decisionmaking ability in the child's development process (Grolnick et al., 1991) and high social and emotional adaptation (Kenney-Benson and Pomerantz, 2005). In addition, autonomy is seen as one of the basic psychological needs for psychological well-being according to Self-Determination Theory (Deci and Ryan, 2008; Ryan and Deci, 2000). Helicopter Parenting and Autonomy Supporting Behaviour Scale examines autonomy supporting behaviours along with helicopter parenting behaviours and differs from other scales developed in this respect.

There are a few different measurement tools developed to examine helicopter parenting. However from the perspective of university students, such scales need to be different according to the developmental needs of this age group, the literature reveals that the developed measurement tools generally focus on the control and participation dimensions of the parents but not the autonomy dimension which is critical for this age group. The concept of helicopter parenting has recently been studied in the Turkish literature and there are a limited number of research and measurement studies on the subject. However, there is no scale in place to examine the helicopter parenting behaviours in university students and autonomy supporting behaviours that directly affect these behaviours. 
Helicopter parenting behaviours affect university students academically, psychologically and socially. For this purpose, it is considered important to adapt the Helicopter Parenting and Autonomy Supportive Behaviours Scale developed by Schiffrin et al. (2014), which examines helicopter parenting behaviours and autonomy supporting behaviours together. Helicopter Parenting and Autonomy Supportive Behaviours Scale is adapted to Turkish in this study and examined in terms of psychometric features.

\section{Method}

The study group consisted of undergraduate students who were studying in various programs at a foundation university in Ankara during the fall semester of the 2019-2020 academic year. The study group included 488 volunteer students from 5 faculties [Faculty of Education $(n=150)$, Faculty of Fine Arts, Design and Architecture $(n=121)$, Faculty of Communication $(n=55)$, Faculty of Health Sciences $(n=106)$, and Faculty of Economics and Administrative Sciences $(n=56)]$ and 13 undergraduate programs. The convenience sampling method was used in the research.

The study group included $78 \%$ female $(n=381)$ and $22 \%$ male $(n=107)$ students and $58 \%$ of them were 2 nd graders $(n=284), 42 \%$ were 4 th graders $(n=204)$. Helicopter Parenting and Autonomy Supportive Behaviours Scale and demographic information form were used for data collection. Demographic information such as students' gender, grade and faculty were also included in the form.

Helicopter Parenting and Autonomy Supportive Behaviours Scale was developed by Schiffrin et al. (2014) to investigate the effects of helicopter parenting behaviours on university students' psychological well-being based on SelfDetermination Theory. The scale includes 15 items rated on a six-point Likert scale (1: strongly disagree; 6: strongly agree). The lowest score on the scale is 15 and the highest score is 90 . The scale includes two dimensions: helicopter parenting and autonomy supporting behaviours. Helicopter parenting dimension consists of 9 items and autonomy-supportive behaviours dimension consists of 6 items. "When I am home with my mother, I have a curfew (a certain time that I must be home by every night)" is an example of the items in helicopter parenting dimension and autonomysupportive behaviours dimension contains items such as "My mother encourages me to make my own decisions and take the responsibility for the choices I have made".

The Cronbach Alpha internal consistency coefficient for the helicopter parenting dimension is .77 and for the autonomy-supportive behaviours dimension is .71 which means the original scale is valid and reliable in the culture in which it was developed.

The process of adapting the scale started with asking for permission from the researchers who developed the Helicopter Parenting and Autonomy Supportive Behaviours Scale. The scale was translated into Turkish by a group of language specialists and then the Turkish items were translated back to English by three language specialists. After then, a pilot study was conducted and students' feedback 
was asked. Following this feedback, the items were rearranged and the main study was performed. Data was collected by attending the students' classes. After informing the students about the purpose of the study the was applied.

In the study, confirmatory factor analysis was conducted for the construct validity of the scale and the Cronbach Alpha coefficient was calculated for the reliability. Data were analysed by using the JASP V0.14 package program.

\section{Results}

CFA was conducted to test the conformity of the scale with the structure determined in the original scale. First, the assumptions of CFA's were tested. Multidimensional normality was not achieved after controlling the missing data and outliers. ZPRED-ZRESID scatter plots were analysed for homoscedasticity assumption. Analysis revealed that there was no multicollinearity by calculating the variance inflation factors.

After testing the assumptions, confirmatory factor analysis (CFA) was conducted. CFA indicated that the Turkish version had two dimensions of 15 items as in the original scale. Items $1,3,4,7,9,10,11,13$ and 14 were in the helicopter parenting factor, items $2,5,6,8,12$ and 15 were included in the autonomy supporting behaviour factor. It was determined that the modifications made a significant contribution to $\chi^{2}$. The model obtained after the modifications appeared to indicate good fit $\left(\chi^{2}=223.02, \mathrm{df}=87, \chi^{2} / \mathrm{df}=2.56, p<.001\right.$, RMSEA $=.060$, SRMR $=.070$, $\mathrm{CFI}=.97, \mathrm{NNFI}=.96, \mathrm{NFI}=.95, \mathrm{GFI}=.98)$ (Büyüköztürk et al., 2018; Kline, 2011; Tabachnick and Fidell, 2013). The calculated factor loads vary between .32 and .74 . Measurement error values vary between .45 and .90 . Considering all CFA values, the scale items are representative of the model.

Cronbach's Alpha internal consistency coefficient was calculated for reliability. Cronbach's Alpha coefficient, which was .77 and .71 for the original scale subdimensions, respectively, was found as .80 and .80 in the Turkish version. These internal consistency coefficients are taken as evidence for reliability.

As a result of the item analysis, the item-total correlations vary between .31 and .64. A significant difference was found in the $27 \%$ lower-upper group comparisons. Considering these values, that scale items are adequate in predicting subscale total scores and are discriminatory. As a result of all the analyses, the validity and reliability values of the Turkish scale are found to be adequate.

\section{Discussion and Conclusions}

The validity and reliability of the Turkish form of the HAÖDD Scale, which measures the helicopter parenting and autonomy supportive behaviours from the perspective of university students, developed by Schiffrin et al. (2014), was examined in this study. The adaptation process was conducted by using all items in the original form of the scale. To obtain evidence for validity, factor loads and error values from the confirmatory factor analysis were examined and the results revealed that the scale 
had a good fit in the defined factor structure. In the analysis conducted to examine the reliability, the scale showed higher reliability values than the original form. These values are considered as proof that the Turkish form of the scale will make reliable measurements. The results of the item analysis yields that the items have sufficient power to represent the scale and that they are distinctive. As a result, the Turkish form of the scale can be used to measure helicopter parenting and autonomy supporting behaviour levels from the perspective of university students.

Helicopter parenting and autonomy supportive behaviours can be effective in the transition to adulthood and in preparing young people for adult roles and responsibilities, therefore it is important to examine the concept. The ongoing helicopter parenting behaviours of parents to their children in the transition to adulthood have negative academic, social and psychological consequences. Including helicopter parenting content to parent training programs has become a necessity for the healthy development of children and youth.

In addition to the validity and reliability proofs of the scale, this study has some limitations. Repeating the study with a larger and random sample will statistically reinforce the Turkish form. The helicopter parenting behaviours are mostly common in middle and upper-middle socioeconomic levels and more studies are needed to examine it at different socioeconomic levels (Schiffrin, et al., 2014). In addition, evaluating helicopter parenting and autonomy supportive behaviours with different variables in both youth and their parents will be useful in terms of seeing the developmental outcomes.

\section{Ethical Committee Approval}

This research was conducted with the permission of Baskent University Social and Human Sciences and Art Research Board, dated 17.07.2019 and numbered $17162298.600-275$. 